\title{
DIVERSIDADE NO GERMOPLASMA DE MILHO COLETADO NA REGIÃO NORDESTE DO BRASIL
}

\author{
FLAVIA FRANÇA TEIXEIRA ${ }^{1}$, RAMIRO VILIELA DE ANDRADE ${ }^{1}$, ANTONIO CARLOS DE \\ OLIVEIRA $^{1}$, ALEXANDRE DA SILVA FERREIRA ${ }^{1}$, MANOEL XAVIER DOS SANTOS ${ }^{1}$
}

\author{
${ }^{1}$ Pesquisadores, Embrapa Milho e Sorgo. Caixa Postal 151, CEP. 35701-970 Sete Lagoas, MG. E-mail: \\ flavia@cnpms.embrapa.br (autor para correspondência).
}

Revista Brasileira de Milho e Sorgo, v.1, n.3, p.59-67, 2002

\begin{abstract}
RESUMO - No Brasil, a utilização do germoplasma pelos melhoristas é baixa, devido, dentre outros fatores, à falta de informação sobre os acessos, que, quando disponíveis, são inadequadas ou insuficientes. O objetivo deste trabalho foi estudar a divergência genética de 169 acessos, avaliados em Janaúba-MG, tendo-se como base quinze caracters morfológicos do Latin American Maize Project (LAMP II). Foram estimadas distâncias genéticas com base nos caracteres morfológicos e formados agrupamentos para os tipos de grãos duro, semidentado, dentado e farináceo. Os acessos CE004 e CE001, com grãos do tipo semidentado, e AL014 e PE007, com grãos do tipo dentado, foram os de maiores produtividades, juntamente com a testemunha intercalar, BR5011. Os acessos mostraram diferenças entre si para todas as características estudadas, sendo possível indicar germoplasma com atributos de interesse para o melhoramento de plantas. As diferenças encontradas entre os acessos foram empregadas para calcular as distâncias entre eles e agrupá-los. O grupo que apresentou maior divergência entre seus acessos foi o duro, seguido do semidentado, farináceo e dentado. Dentre os acessos do tipo duro, os mais divergentes dos demais foram os acessos BA233 e CE017; dentre os dentados, o que mais divergiu foi o acesso MA012 e, dentre os farináceos, o acesso CE027 foi o que mais se distanciou dos outros componentes do grupo. Quanto ao grupo semidentado, foram formados dois subgrupos: no menor deles foram agrupados os acessos AL024, BA207, BA220, CE001, BA211, RN007, PE045 e PE032, ficando os demais no outro subgrupo.
\end{abstract}

Palavras-chave: Zea mays, pré-melhoramento, recursos genéticos.

\section{MAIZE GERMPLASM DIVERSITY FROM NORTHESTERN REGION OF BRAZIL}

\begin{abstract}
Breeders in Brazil do not use the germplasm frequently due to several factors, including the lack of information about the accesses which, when available, are inadequate or insufficient. This research aims at estimating the genetic divergence of 169 accessions of germplasm evaluated at The Second Latin American Maize Project (LAMP II) in JanaubaMG using fifteen morfological characters. These characters were used to estimate the genetic distance between the accessions and to form clusters for each grain type. The accessions CE004 and CE001 with flint grains and the AL014 and PE007 with dent grains together with the check, BR5011, reached the highest yield. All the germplasm evaluated showed differences, so it was possible to identify germplasm with special characters usually required by the plant breeding and the difference between the accessions was useful to evaluate the divergence between the accesses and to cluster them. The flint group was the most divergent followed by
\end{abstract}


the semident, floury and dent groups. The accessions BA233 and CE017 were the most divergent in the flint grain group, the MA012 was the most divergent in dent grain and the CE027 was the most divergent in floury grain. The group with semident grains was divided in two: one of the subgroups held the accessions AL024, BA207, BA220, CE001, BA211, RN007, PE045 and PE032 and the other one held the others.

Key words: Zea mays, pre-breeding, genetic resources.

O milho(Zea mays L.) é provavelmente uma das espécies cultivadas com maior diversidade genética (Paterniani et al., 2000). Há grande variabilidade genética tanto para caracteres relacionados a adaptação ambiental, quanto para aqueles que não influenciam na vantagem adaptativa. O milho é cultivado em condições ambientais distintas, desde o extremo norte ao extremo sul, desde baixas altitudes até altitudes superiores a $2.500 \mathrm{~m}$. Por essa razão, encontra-se na espécie variabilidade genética para adaptação às mais variadas condições ambientais. Além da ampla variabilidade para adaptação ambiental, encontra-se no milho variabilidade para quase todos os caracteres da planta, dos grãos e da espiga (Paterniani et al., 2000).

A inestimável riqueza genética do milho vem sendo conservada nos bancos ativos de germoplasma (BAG). No Brasil, a utilização desse tipo de germoplasma é baixa. Apenas 14\% dos melhoristas recorrem regularmente aos bancos de germoplasma e $18 \%$ nunca os usam (Nass e Paterniani, 2000). Entre as razões do uso limitado dos BAGs pelos melhoristas estão o interesse por suas próprias coleções de trabalho, o desejo de trabalhar com materiais mais avançados e as informações sobre os acessos, consideradas inadequadas e insuficientes, quando disponíveis. Essaúltima é a mais importante e a mais fácil de ser superada pois, apenas avaliações e publicação de resultados já são suficientes para aumentar o conhecimento e o interesse sobre as coleções (Andrade, 2000).

O Latin American Maize Project (LAMP) tem como objetivo avaliar germoplasma de milho em diversas condições ambientais e fornecer informações para que os melhoristas possam incorporar novas fontes gênicas para o desenvolvimento de variedades e híbridos, ampliando, assim, a base genética dos materiais trabalhados pelo melhoramento. Com as informações geradas no LAMP, é esperado que sejam disponibilizadas fontes de germoplasma que venham a ampliar a diversidade genética das coleções de trabalho do melhorista e a área de adaptação das cultivares, levando à utilização mais eficiente dos recursos genéticos e físicos de uma região (Centro, 1998).

O LAMP, em sua primeira edição, 19861991, avaliou, em etapa preliminar, 11.929 acessos em 13 países, selecionou os mais adaptados e, em mais quatro fases de avaliação, selecionou acessos considerando os seus desempenhos, não apenas per se, mas também em cruzamentos. Dessa forma, dentre outras conclusões, foram identificados os acessos BOZM-468, CMS0508III, SE33 e PAZM08063, com bom desempenho em solos ácidos brasileiros (Centro, 1998).

Alguns anos após a conclusão do LAMP I, teve início o LAMP II, considerando novos acessos em diversas condições ambientais, envolvendo Argentina, Bolívia, Chile, Colômbia, Estados Unidos, Guatemala, Paraguai, Peru, Porto Rico, Uruguai e Venezuela, além do Brasil.

O objetivo deste trabalho foi avaliar o germoplasma que participou do LAMP II em Janaúba, MG, quanto a diversos caracteres morfológicos e, com base nesses caracteres, estimar a divergência genética entre os acessos, visando 
fornecer informações para os programas de melhoramento de plantas.

\section{Material e Métodos}

Foram avaliados 168 acessos originários da região Nordeste do Brasil, além do acesso Camélia, que é proveniente do Chile. Adotou-se como testemunha a cultivar BR 5011, desenvolvida por seleção intrapopulacional no Pool 21 do CIMMYT, na região Nordeste, onde é amplamente cultivada. $\mathrm{Na}$ Tabela 1, estão apresentados os acessos avaliados neste trabalho e suas respectivas identificações.

O delineamento experimental usado foi o látice simples $13 \times 13$, com uma testemunha interca$\operatorname{lar}(\mathrm{Ti})$. As parcelas experimentais constaram de duas fileiras de 5,0 m, espaçadas de 0,90 m. O ensaio foi conduzido no Campo Experimental do Gorutuba, pertencente à Embrapa Milho e Sorgo, localizado em Nova Porteirinha, Norte de Minas Gerais. Essa região caracteriza-se por possuir clima predominantemente seco e solo do tipo latossolo amarelo.

Foram tomados dados em dez plantas e de dez espigas por parcela, das seguintes características: número de dias para florescimento masculino e feminino, altura média de planta e da espiga, tipo de endosperma (duro, semidentado, dentado e farináceo), comprimento e diâmetro médios de espiga, comprimento e largura médios de grão. Para cada parcela foi tomado o número de plantas acamadas, o número de plantas quebradas, o número de espigas e os pesos de espigas e de grãos, expressos em gramas, e as reações dos acessos em relação à ocorrência natural das seguintes doenças (ferrugemPuccinia polysora; mancha por phaeosphaeriaPhaeosphaeria maydis; helmintosporiose Exerohilum turcicum, utilizando uma escala de notas para severidade de doenças: 1 - ausência de doença, 2 - presença de doença em poucas plantas, 3 - ocorrência da doença em mais de $50 \%$ das plantas, porém com baixa severidade, 4 - ocorrência da doença em $100 \%$ das plantas, com até $25 \%$ da área foliar afetada, 5 - doença severa, semelhante ao item 4, porém com mais de $25 \%$ da área foliar afetada.

As análises estatísticas foram feitas por meio do programa SAS (SAS, 1993). Primeiramente, foram realizadas as análises de variância e obtidas as médias ajustadas de cada característica avaliada. Com base na matriz de correlações fenotípicas entre as variáveis consideradas e com o auxílio do programa GENES, foi examinada a multicolinearidade entre as variáveis. Em seguida, foi feito um primeiro agrupamento, separando os acessos pelo seu tipo de grão, em quatro grupos: duro, semidentado, dentado e farináceo. De cada grupo, com base nas médias das demais características analisadas e com o emprego do programa GENES (Cruz, 2001), foram estimadas as distâncias de Mahalanobis entre os acessos (Cruz e Regazzi, 1994). Com base nas matrizes de distâncias obtidas, foram construídos os dendrogramas, pelo método Single Linkage Cluster Analysis, obtendo um agrupamento para cada tipo de grão.

\section{Resultados e Discussão}

Os acessos avaliados apresentaram diferenças significativas entre médias para todas as características consideradas, indicando grande variabilidade entre os acessos considerados.

Foi identificada colinearidade fraca entre as doze variáveis usadas, indicando ausência de efeito adverso sobre as estimativas. Dessa forma, a correlação fenotípica entre as variáveis é baixa ou inexistente, não comprometendo as estimativas de distância entre os acessos.

A menor distância foi encontrada entre os acessos 40 (BA216) e 144 (PE041), ambos com grãos semidentados. A maior distância foi obtida entre os acessos 3 (AL022) e 135 (PE032), ambos do grupo com grão do tipo semidentado, mostrando grande variabilidade nesse grupo, que, possivelmente, 
TABELA 1. Identificação dos acessos avaliados. Embrapa Milho e Sorgo, Sete Lagoas, MG. 2002.

\begin{tabular}{|c|c|c|c|c|c|c|c|c|c|}
\hline \multicolumn{10}{|c|}{ Acessos com grãos do tipo duro } \\
\hline Número & Nome & Número & Nome & Número & Nome & Número & Nome & Número & Nome \\
\hline $\mathrm{Ti}$ & BR5011 & 68 & Camélia & 84 & CE015 & 108 & CE039 & 143 & PE040 \\
\hline 57 & BA233 & 69 & C. S. Lagoas & 86 & CE017 & 119 & PB018 & 159 & PE056 \\
\hline 61 & BA237 & 83 & CE014 & 106 & CE037 & 121 & $\mathrm{~PB} 020$ & 166 & RN012 \\
\hline 66 & BA242 & & & & & & & & \\
\hline \multicolumn{10}{|c|}{ Acessos com grãos do tipo semidentado } \\
\hline Número & Nome & Número & Nome & Número & Nome & Número & Nome & Número & Nome \\
\hline 3 & AL022 & 26 & BA202 & 55 & BA231 & 80 & CE011 & 122 & PB021 \\
\hline 4 & AL023 & 28 & BA204 & 56 & BA232 & 81 & CE012 & 124 & PB023 \\
\hline 5 & AL024 & 29 & BA205 & 58 & BA234 & 87 & CE018 & 127 & PB026 \\
\hline 6 & AL025 & 31 & BA207 & 59 & BA235 & 88 & CE019 & 132 & PE029 \\
\hline 7 & AL026 & 33 & BA209 & 60 & BA236 & 89 & CE020 & 135 & PE032 \\
\hline 9 & AL028 & 35 & BA211 & 62 & BA238 & 90 & CE021 & 136 & PE033 \\
\hline 11 & AL030 & 36 & $\mathrm{BA} 212$ & 65 & BA241 & 91 & CE022 & 137 & PE034 \\
\hline 14 & AL033 & 38 & BA214 & 67 & BA243 & 94 & CE025 & 139 & PE036 \\
\hline 15 & AL037 & 40 & BA216 & 70 & CE001 & 98 & CE029 & 141 & PE038 \\
\hline 17 & BA011 & 44 & BA220 & 71 & CE002 & 114 & PB013 & 142 & PE039 \\
\hline 18 & BA013 & 45 & BA221 & 73 & CE004 & 115 & PB014 & 144 & PE041 \\
\hline 19 & BA057 & 50 & BA226 & 75 & CE006 & 116 & PB015 & 145 & PE042 \\
\hline 21 & BA195 & 51 & BA227 & 77 & CE008 & 117 & AL030 & 146 & PE043 \\
\hline 23 & BA199 & 52 & BA228 & 78 & CE009 & 118 & PB017 & 147 & PE044 \\
\hline 25 & BA201 & 53 & BA229 & 79 & CE010 & 120 & PB019 & 148 & PE045 \\
\hline 149 & PE046 & 152 & PE049 & 157 & PE054 & 161 & RN007 & 165 & RN011 \\
\hline 150 & PE047 & 154 & PE051 & 158 & PE055 & 163 & RN009 & 167 & SE009 \\
\hline 151 & PE048 & 155 & PE052 & 160 & RN006 & 164 & RN010 & 168 & SE037 \\
\hline \multicolumn{10}{|c|}{ Acessos com grãos do tipo dentado } \\
\hline Número & Nome & Número & Nome & Número & Nome & Número & Nome & Número & Nome \\
\hline 1 & AL008 & 32 & BA208 & 64 & BA240 & 104 & CE035 & 129 & PB028 \\
\hline 2 & AL014 & 37 & BA213 & 72 & $\mathrm{CE} 003$ & 107 & CE038 & 130 & PB029 \\
\hline 8 & AL027 & 39 & BA215 & 74 & CE005 & 109 & MA012 & 131 & PE007 \\
\hline 10 & AL029 & 41 & $\mathrm{BA} 217$ & 76 & $\mathrm{CE} 007$ & 110 & MA019 & 133 & PE030 \\
\hline 12 & AL031 & 42 & BA218 & 82 & CE013 & 111 & MA4009 & 134 & PE031 \\
\hline 13 & AL032 & 43 & BA219 & 85 & CE016 & 112 & MA4040 & 138 & PE035 \\
\hline 16 & BA008 & 46 & BA222 & 86 & CE017 & 113 & PB012 & 140 & PE037 \\
\hline 20 & BA143 & 47 & BA223 & 92 & CE023 & 123 & PB022 & 153 & PE050 \\
\hline 22 & BA198 & 48 & BA224 & 93 & CE024 & 125 & PB024 & 156 & PE053 \\
\hline 24 & BA200 & 49 & BA225 & 95 & CE026 & 126 & PB025 & 162 & RN008 \\
\hline 27 & BA203 & 54 & BA230 & 103 & CE034 & 128 & PB027 & 169 & SE038 \\
\hline 30 & BA206 & 63 & BA239 & & & & & & \\
\hline \multicolumn{10}{|c|}{ Acessos com grãos do tipo farináceo } \\
\hline Número & Nome & Número & Nome & Número & Nome & Número & Nome & Número & Nome \\
\hline 105 & CE036 & 100 & CE031 & 34 & BA210 & 101 & CE032 & 102 & CE033 \\
\hline 96 & CE027 & 99 & CE030 & 97 & CE028 & & & & \\
\hline
\end{tabular}


é devido à variabilidade inerente ao grupo semidentado e, também, por esse grupo ter grande número de representantes neste trabalho. Além dos acessos 3 e 135, é importante destacar que os acessos 83 (CE014) e 159 (PE056) do grupo duro, 133 (PE030) do grupo dentado e 96 (CE027) do grupo farináceo foram responsáveis pelas maiores estimativas de distância. Por essa razão, esses acessos são mais divergentes dos demais e, numa etapa posterior, deverão ser avaliados quanto à capacidade combinatória, juntamente com os acessos de alta produtividade, apesar de nenhum desses acessos mais divergentes ter-se destacado em relação à produtividade.

Todos os grupos considerados nessa avaliação mostraram grande divergência entre seus acessos. Dentre eles, destacou-se o tipo de grão duro, cujos acessos apresentaram a maior diversidade genética entre si, seguido dos grupos semidentado, farináceo e dentado. A menor diversidade genética do grupo dentado em relação às de outros tipos de grão já havia sido constatada por Abadie et al. (1997), ao analisar dados para a formação da Coleção Núcleo de milho no Brasil.

No agrupamento obtido para os acessos com grãos tipo duro (Figura 1), foi possível verificar claramente a grande divergência dos acessos 57 (BA233) e 86 (CE017) em relação aos demais, resultando na formação de dois grupos: um apenas com os acessos 57 e 86 e outro com os demais acessos.

Neste trabalho, o maior número de acessos considerados pertence ao grupo semidentado. Por essa razão, para esses acessos, foi possível obter agrupamentos com maior número de acessos. Foram formados dois grupos (Figura 2), o primeiro foi composto pelos acessos 5 (AL024), 31 (BA207), 44 (BA220), 70 (CE001), 35 (BA211), 161 (RN007), 148 (PE045) e 135 (PE032) e, no segundo grupo, estiveram todos os demais acessos com tipo de grãos semidentados. O maior número

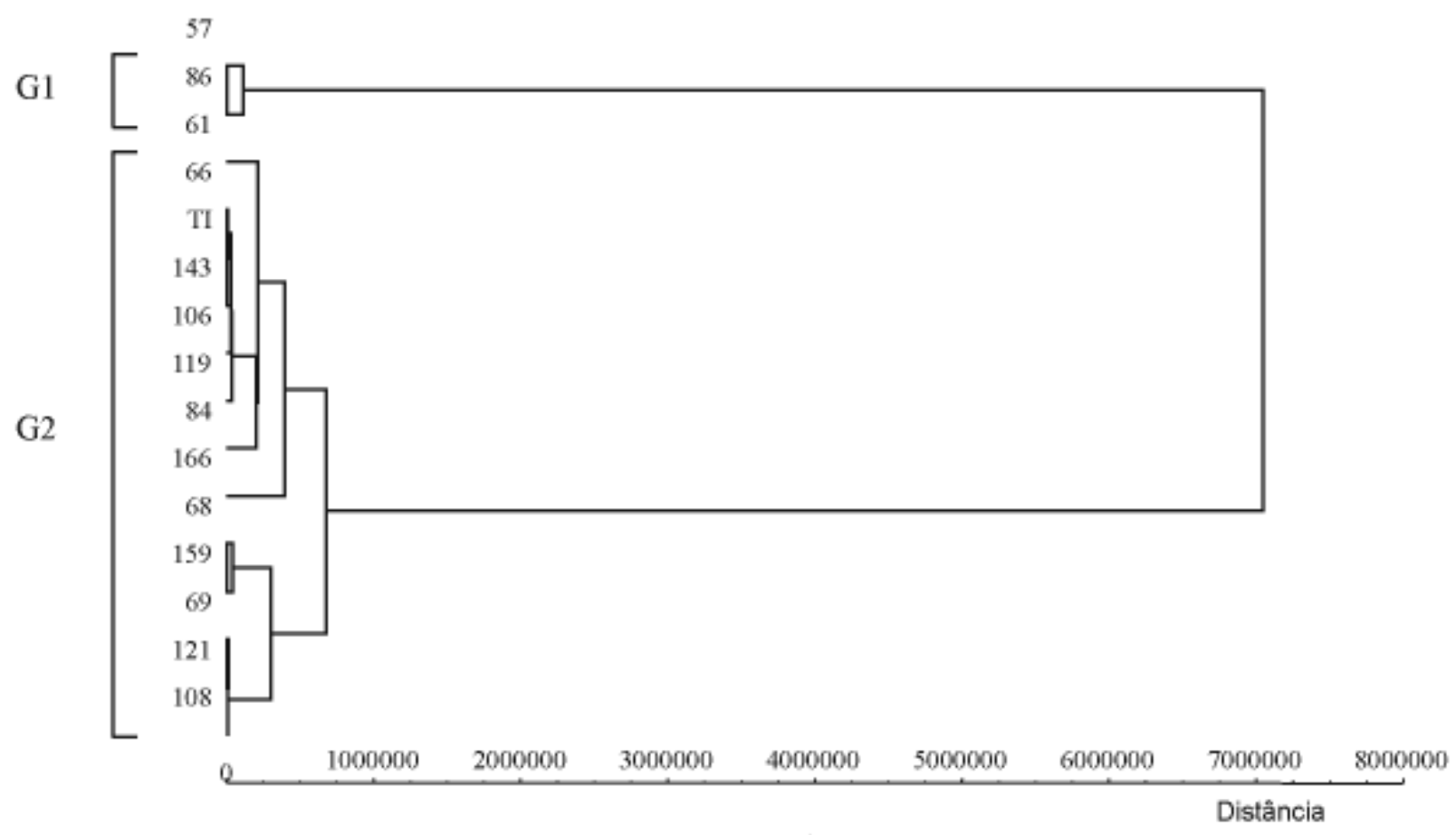

FIGURA 1. Agrupamento obtido para os acessos do tipo duro, com base em caracteres morfológicos. Embrapa Milho e Sorgo, Sete Lagoas, MG, 2002. 


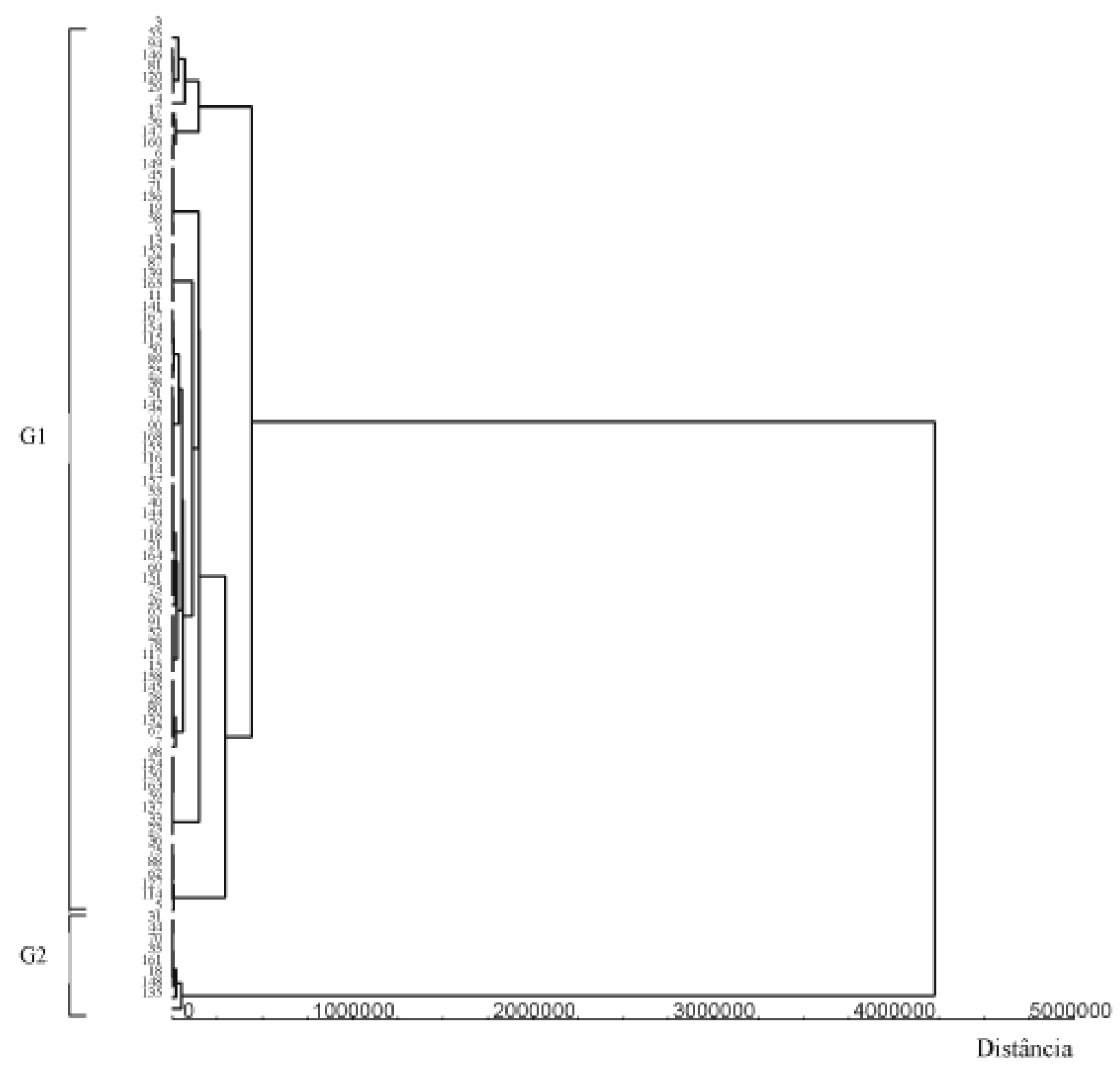

FIGURA 2. Agrupamento obtido para os acessos do tipo semidentado, com base em caracteres morfológicos. Embrapa Milho e Sorgo, Sete Lagoas, MG, 2002.

de representantes dentro desse grupo permitiu que fossem identificados acessos de grande divergência, porém, de maneira geral, os acessos do grupo semidentado foram menos divergentes entre si do que os dos grupos duro, dentado e farináceo.

Para o grupo dentado, também foram considerados muitos acessos nessa avaliação. Foram observados dois grupos (Figura 3), um com apenas o acesso 109 (MA012) e outro com os demais acessos. Por essa razão, foi constatada menor diversidade genética dentro do grupo formado pelos acessos com tipo de grão dentado. Essa menor diversidade já era esperada, com base no trabalho de Abadie et al. (1997), que analisaram dados para formação da coleção núcleo de milho no Brasil. 


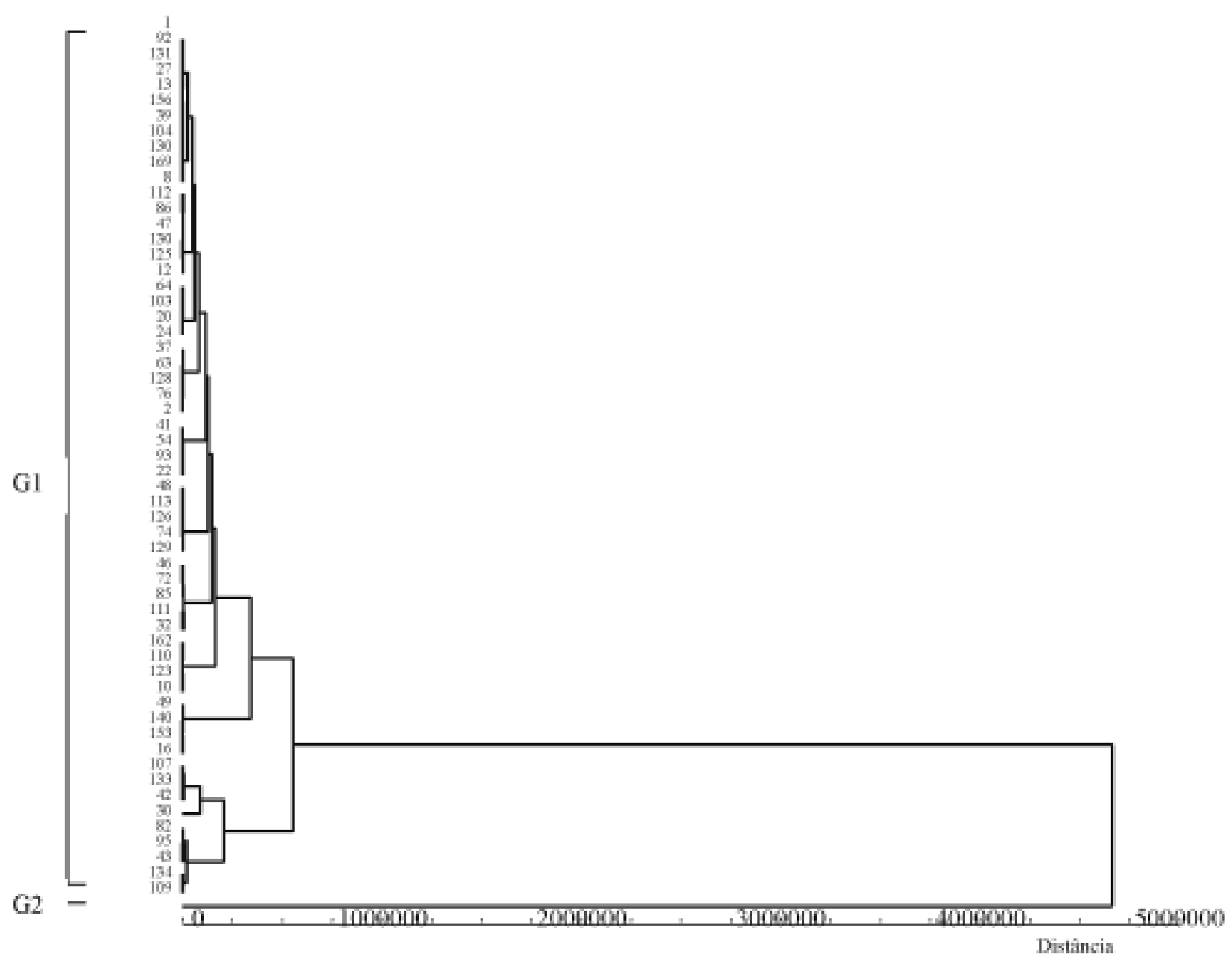

FIGURA 3. Agrupamento obtido para os acessos do tipo dentado, com base em caracteres morfológicos. Embrapa Milho e Sorgo, Sete Lagoas, MG, 2002.

Para o tipo de grão farináceo, também foram encontrados dois grupos (Figura 4). Apenas o acesso 96 (CE027) foi considerado como pertencente a um grupo distinto em relação aos demais acessos.

Os acessos de maiores produtividades foram CE004 e CE001, com grãos do tipo semidentado, e AL014 e PE007, com grãos do tipo dentado, juntamente com a testemunha intercalar, BR5011.

As médias de cada grupo de acesso identificado no dendrograma estão apresentadas na Tabela 2. O grupo $2(\mathrm{G} 2)$, com acessos com tipo de grãos duros, mostrou altura de planta e de espiga inferiores, precocidade no florescimento e maior produtividade de grãos em relação ao grupo $1(\mathrm{G} 1)$, do mesmo tipo de grãos. Quanto aos acessos com grãos do tipo semidentado, foram observados, em média, no grupo 2 (G2), menores alturas de planta e de espiga, menor número de dias para atingir o florescimento e maior produtividade de grãos, quando em comparação com o grupo 1 (G1), de acessos com grãos do tipo semidentado. Já os acessos com grãos do tipo dentado, agrupados em G1, apresentaram menores alturas de planta e de espiga e menor período para florescimento e os agrupados em G2 apresentaram produtividade superior em relação aos 


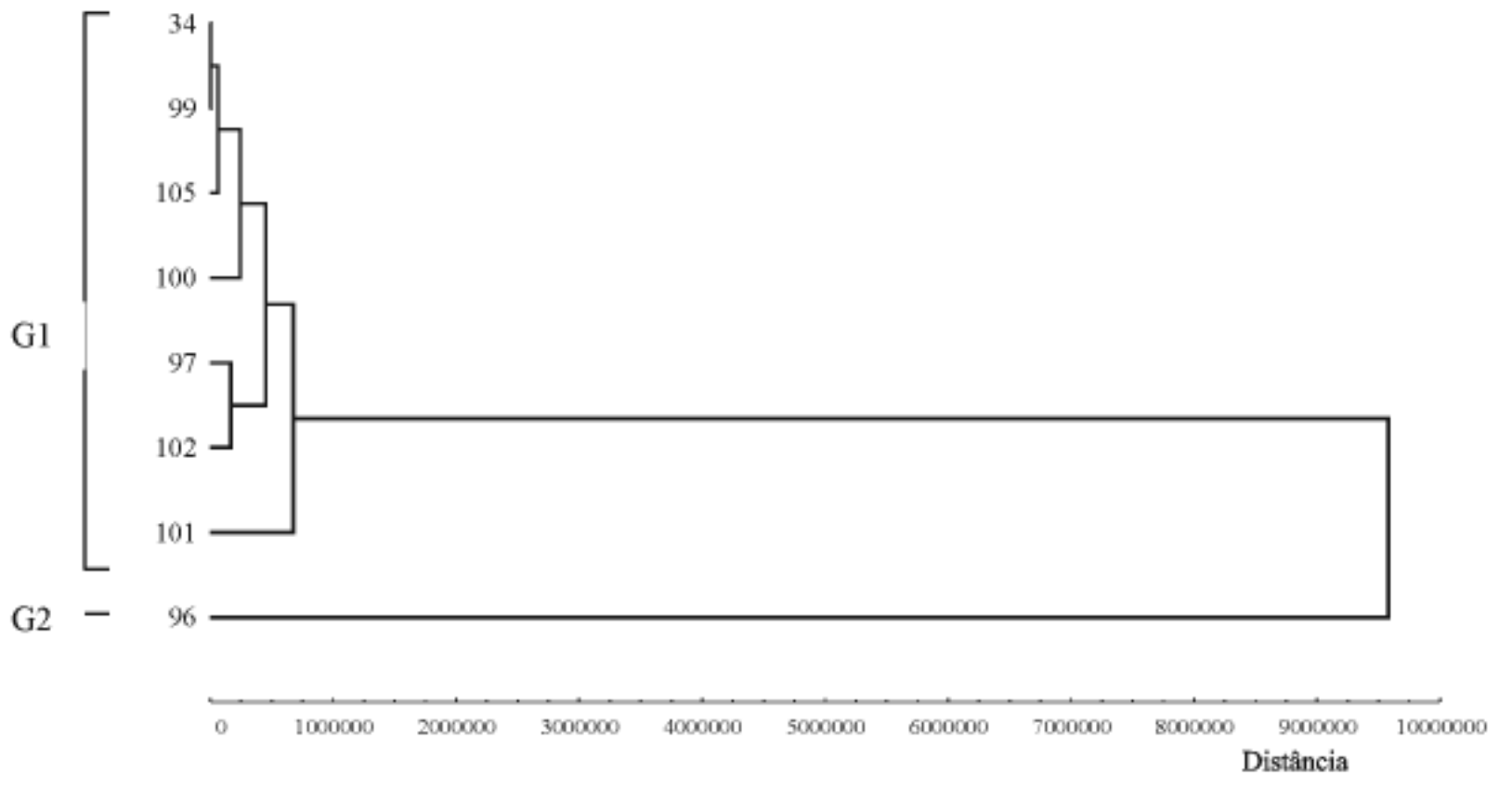

FIGURA 4. Agrupamento obtido para os acessos do tipo farináceo, com base em caracteres morfológicos. Embrapa Milho e Sorgo, Sete Lagoas, MG, 2002.

TABELA 2. Médias dos grupos de acessos. Embrapa Milho e Sorgo, Sete Lagoas, MG. 2002.

\begin{tabular}{|c|c|c|c|c|c|c|c|c|c|c|c|c|}
\hline \multirow{2}{*}{ Grupo } & \multicolumn{2}{|c|}{ Altura de: (cm) } & \multicolumn{2}{|c|}{$\begin{array}{c}\text { No. de dias para } \\
\text { florescimento }\end{array}$} & \multicolumn{4}{|c|}{ Espiga } & \multicolumn{3}{|c|}{ Grầo } & \multirow{2}{*}{$\begin{array}{c}\text { Nota } \\
\text { Sanidade }\end{array}$} \\
\hline & Planta & Espiga & Masculino & Feminino & Número & $\begin{array}{l}\text { Peso } \\
(\mathrm{Kg})\end{array}$ & $\begin{array}{l}\text { Comp. } \\
(\mathrm{cm})\end{array}$ & $\begin{array}{r}\text { Diâm. } \\
(\mathrm{mm})\end{array}$ & $\begin{array}{l}\text { Peso } \\
(\mathrm{Kg}) \\
\end{array}$ & $\begin{array}{c}\text { Comp. } \\
(\mathrm{mm})\end{array}$ & $\begin{array}{l}\text { Larg. } \\
(\mathrm{mm}) \\
\end{array}$ & \\
\hline \multicolumn{13}{|c|}{ Acessos com grãos do tipo duro } \\
\hline Gl & 264,9 & 159,1 & 62,3 & 67,0 & 35,7 & 1,2 & 12,5 & 32,3 & 1,0 & 8,3 & 8,1 & 6,8 \\
\hline G2 & 266,7 & 148,4 & 56,8 & 61,3 & 37,2 & 2,0 & 13,2 & 34,5 & 1,6 & 8,4 & 7,6 & 6,6 \\
\hline \multicolumn{13}{|c|}{ Acessos com grãos do tipo semidentado } \\
\hline G1 & 275,5 & 161,4 & 59,3 & 63,8 & 31,5 & 1,7 & 13,5 & 37,0 & 1,4 & 9,3 & 8,4 & 6,3 \\
\hline G2 & 270,9 & 159,6 & 57,6 & 61,9 & 29,9 & 2,0 & 13,7 & 38,4 & 1,6 & 9,5 & 8,7 & 6,4 \\
\hline \multicolumn{13}{|c|}{ Acessos com grãos do tipo dentado } \\
\hline Gl & 278,6 & 162,7 & 58,3 & 62,9 & 31,6 & 2,3 & 13,7 & 39,1 & 1,9 & 10,0 & 8,8 & 6,5 \\
\hline G2 & 302,8 & 192,8 & 62,2 & 65,0 & 50,7 & 3,9 & 15,5 & 43,1 & 3,3 & 10,8 & 8,6 & 7,4 \\
\hline \multicolumn{13}{|c|}{ Acessos com grãos do tipo farináceo } \\
\hline Gl & 273,1 & 162,0 & 61,2 & 65,8 & 22,9 & 0,9 & 12,4 & 35,6 & 0,7 & 8,9 & 8,4 & 5,3 \\
\hline G2 & 256,9 & 158,0 & 63,7 & 67,4 & 18,1 & 0,6 & 14,0 & 34,4 & 0,6 & 8,8 & 8,4 & 5,2 \\
\hline
\end{tabular}


demais. O acesso 96, com grãos farináceos, que foi o mais divergente no agrupamento, apresentou menor altura de planta e de espiga, menor precocidade e baixa produtividade em relação aos acessos com grãos farináceos.

Dessa forma, foi possível estimar médias dos acessos para diversos caracteres de importância agronômica e identificar os acessos mais divergentes geneticamente dos demais, que, por essa razão, têm potencial para serem inseridos em novos ciclos de avaliação que visem ampliar a base genética dos seus materiais elite e maximizar a heterose. Com essa e outras avaliações futuras, espera-se que se agreguem informações sobre o germoplasma de milho, superando a carência de informações a respeito do germoplasma (Andrade, 2000).

\section{Conclusões}

Os acessos CE004 e CE001, com grãos do tipo semidentado, e AL014 e PE007, com grãos do tipo dentado, foram os de maiores produtividades, juntamente com a testemunha intercalar, BR5011.

Os acessos mostraram diferenças entre si para todas as características estudadas, sendo possível indicar germoplasma com atributos que normalmente são de interesse do melhoramento de plantas; as diferenças encontradas entre os acessos foram empregadas para calcular as distância entre eles e agrupá-los.

O grupo que apresentou maior divergência entre seus acessos foi o duro, seguido do semidentado, farináceo e dentado.

Dentre os acessos do tipo duro, os mais divergente dos demais foram os acessos 57 (BA233) e 86 (CE017); dentre os dentados, o que mais divergiu foi o acesso 109(MA012) e, dentre os farináceos, o acesso 96 (CE027) foi o que mais se distanciou dos outros componentes do grupo. Quanto ao grupo semidentado, foram formados dois grupos, no menor deles foram agrupados os acessos: 5 (AL024), 31 (BA207), 44 (BA220), 70 (CE001), 35 (BA211), 161 (RN007), 148 (PE045) e 135 (PE032).

\section{Literatura Citada}

ABADIE, T.; MAGALHÃES, J.; CORDEIRO, C. M. T.; PARENTONI, S. N.; ANDRADE, R.V. Obtenção e tratamento analítico de dados para organizar a coleção nuclear de milho. Sete Lagoas: EMBRAPA-CNPMS, 1997. 7p. (EMBRAPA-CNPMS. Comunicado Técnico, 20).

ANDRADE, R. V. Importância e uso de germoplasma para o melhoramento genético vegetal - milho. In: UDRY, C.V.; DUARTE, W.F. (Org.) Uma história brasileira do milho -0 valor de recursos genéticos. Brasília: Paralelo 15, 2000. p.79-84.

CENTRO DE INFORMATICA PARA LA INVESTIGACION AGRICOLA. Projecto latinoamericano del maiz (LAMP):informe final. Lima, [1998 ?]. 52p

CRUZ, C.D.; REGAZZI, A.J. Modelos biométricos aplicados ao melhoramento. Viçosa: UFV, 1994. 390 p.

CRUZ, C.D. Programa GENES, versão windows. Viçosa: UFV, 2001. 672p.

NASS, L.N.; PATERNIANI, E. Perspectivas do pré-melhoramento do milho. In: UDRY, C.V.; DUARTE, W.F. (Org.) Uma história brasileira do milho - o valor de recursos genéticos. Brasília: $\mathrm{Pa}-$ ralelo 15, 2000. p.43-63.

PATERNIANI, E.; NASS, L.N.; SANTOS, M.X. O valor dos recursos genéticos de milho para o Brasil: Umaabordagem histórica dautilizaçãode germoplasma. In: UDRY, C.V.; DUARTE, W.F. (Org.) Uma história brasileira do milho - o valor de recursos genéticos. Brasília: Paralelo 15, 2000. p.11-41.

SCOTT, A. J.; KNOTT, M.A. A cluster analysis method for grouping means in the analysis of variance. Biometrics, Washington, v. 30, n.3, p. 507-512, Sept. 1974.

SAS INSTITUTE. SAS System. Cary, 1993. 18v. 